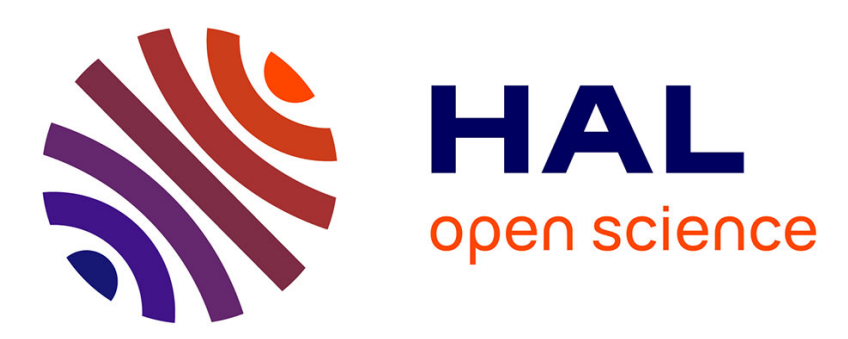

\title{
Complex roles of Rabs and SNAREs in the secretory pathway and plant development: a never-ending story
}

\author{
Alexandre Martiniere, Patrick Moreau
}

\section{To cite this version:}

Alexandre Martiniere, Patrick Moreau. Complex roles of Rabs and SNAREs in the secretory pathway and plant development: a never-ending story. Journal of Microscopy, 2020, 280 (2), pp.140-157. 10.1111/jmi.12952 . hal-02967217

\section{HAL Id: hal-02967217 https://hal.inrae.fr/hal-02967217}

Submitted on 16 Dec 2020

HAL is a multi-disciplinary open access archive for the deposit and dissemination of scientific research documents, whether they are published or not. The documents may come from teaching and research institutions in France or abroad, or from public or private research centers.
L'archive ouverte pluridisciplinaire $\mathbf{H A L}$, est destinée au dépôt et à la diffusion de documents scientifiques de niveau recherche, publiés ou non, émanant des établissements d'enseignement et de recherche français ou étrangers, des laboratoires publics ou privés. 
1 COMPLEX ROLES OF RABS AND SNARES IN THE SECRETORY PATHWAY AND PLANT DEVELOPMENT: A NEVER-ENDING STORY ...

Alexandre Martinière ${ }^{1,{ }^{*}}$ and Patrick Moreau ${ }^{2, *}$

${ }^{1}$ BPMP, Univ Montpellier, CNRS, INRAE, Montpellier SupAgro, Montpellier, France

7

${ }^{2}$ CNRS and University of Bordeaux, UMR 5200 Membrane Biogenesis Laboratory, INRA

Bordeaux, 33140 Villenave d'Ornon, France.

9

${ }^{\star}$ Corresponding authors

Alexandre Martinière

(alexandre.martiniere@cnrs.fr),

Patrick

Moreau

(patrick.moreau@u-bordeaux.fr)

\section{Summary}

Membrane trafficking is critical for cell compartmentalisation, which allows for the maintenance of specialized environments required for specific cellular activities. To achieve this goal, cells need to tightly regulate vesicular transport between donor and acceptor compartments. This process involves several different protein families; including the SNAREs (65 genes) and small GTPases Rabs (57 genes), which show the highest number of isoforms and therefore are of most interest. We will focus on the roles of these proteins in the ER-Golgi-Plasma membrane pathway to illustrate how Rabs and SNAREs mediate a specific set of functions.

\section{Keywords}

Plant, Rab, SNARE, ER, Golgi, Plasma membrane, membrane trafficking. 


\section{INTRODUCTION}

Professor Chris Hawes was, throughout his tremendous career, passionate about the study of cell compartmentalisation. Membrane trafficking through the secretory pathway from the endoplasmic reticulum (ER), to the Golgi and to the plasma membrane (PM) contributes to cell compartmentalisation. This is critical for many aspects of plant development (cell elongation, cell division, cell wall formation, organelle morphodynamics, and homeostasis, plant responses to environmental stresses, and so forth).

Contrary to mammalian cells where the Golgi apparatus is a singular organelle associated with the microtubule organizing center (MTOC), the Golgi apparatus in plant cells is made of several distinct individual stacks (with each collection of stacks comprising a single Golgi body, with potentially hundreds of Golgi bodies being present in each cell). Professor Hawes et al. determined that these Golgi bodies move on an ER-actin network (Boevink et al., 1998) and interact with ER export sites, constituting what was termed "single mobile secretory units" (daSilva et al., 2004). Therefore, the ER-Golgi interface in the secretory pathway of plant cells cannot be considered analogous to what is known and described in mammals (Brandizzi and Barlowe, 2013).

Vesicle trafficking through the secretory pathway allows for each subcellular compartment to be composed of unique combinations of proteins and lipids. This compartmentalisation of cells permits the maintenance of specialized environments required for specific cellular activities. To achieve this goal, cells need to tightly regulate a set of events. Vesicle transport generally requires formation and budding of the vesicle from the donor membrane (with appropriately sorted cargos), 
correct/specific targeting of the vesicle to the acceptor membrane, and finally fusion of the vesicle with this target membrane (Söllner et al., 1993; Kim and Brandizzi, 2012; Brandizzi and Barlowe, 2013). At each step, several different protein families are involved: budding factors, small GTPases Sar/Arf (secretion-associated Rasrelated protein/ADP-ribosylation factor) and Rab/Ypt (Ras-related in brain/ Yeast protein transport), GTPase effectors, coat proteins, tethering factors, SNAREs (soluble $\mathrm{N}$-ethylmaleimide-sensitive-factor attachment protein receptor), to name just a few (Rutherford and Moore, 2002; Vernoud et al., 2003; Sutter et al., 2006; Lipka et al., 2007; Moreau et al., 2007; Sanderfoot, 2007; Woollard and Moore, 2008; Saito and Ueda, 2009; Kim and Brandizzi, 2012; Brandizzi and Barlowe, 2013; Singh and Jürgens, 2018). The protein families comprising the trafficking machinery are well conserved and, at the ER-Golgi interface, anterograde trafficking is thought to be mediated by the coat proteins of the COPII machinery, and the retrograde Golgi to ER trafficking with the coat proteins of the COPI machinery, with these two pathways being interdependent (Stefano et al., 2006). We will see later that this scheme continues to evolve in its structure and that our view and understanding of the ERGolgi interface in plant cells continue to progress.

Professor Hawes has worked on several members of these different protein families, especially on Rab proteins with Professor lan Moore in Oxford, and to some extent on SNAREs with the team of Dr. Patrick Moreau in Bordeaux. This review will focus on these two families of proteins, and their essential function in the ER-Golgi-Plasma membrane pathway and various aspects of plant life and development.

Two classes of Ras-like small GTPases participate in the overall mechanism of membrane trafficking. First, Sar/Arf are required for vesicle formation at the donor membrane, and then Rab/Ypt are required for targeting and/or tethering of transport 
vesicles to the acceptor compartment (Rutherford and Moore, 2002; Vernoud et al., 2003; Woollard and Moore, 2008; Saito and Ueda, 2009). Finally, vesicle fusion to the acceptor membrane is ensured by proteins known as SNAREs (Sutter et al., 2006; Lipka et al., 2007; Moreau et al., 2007; Sanderfoot, 2007; Saito and Ueda, 2009; Kim and Brandizzi, 2012; Brandizzi and Barlowe, 2013). The number of Rab/Ypt and SNARE genes are usually significantly higher than Sar/Arf. For example, in Arabidopsis, 57 Rab genes and 65 SNARE genes are present in the genome whereas only $16 \mathrm{Sar} / \mathrm{Arf}$ exist. From a phylogenetic point of view the diversity in Rab and SNARE genes was often associated with multicellularity and a high complexity of internal membranes and organelles (Sanderfoot, 2007; Woollard and Moore, 2008; Saito and Ueda, 2009; Kim and Brandizzi, 2012; Brandizzi and Barlowe, 2013). Compared to animals and fungi in terms of evolution, plants show both high conservation of some ancestral genes but also specialization of some, leading to novel functions of many proteins (Barlow and Dacks, 2018). This observation raised a fundamental question as to the functional role of such complexity, and especially how Rabs and SNAREs are able to achieve so many different specific functions (Lipka et al., 2007; Sanderfoot, 2007; Woollard and Moore, 2008; Saito and Ueda, 2009; Kim and Brandizzi, 2012; Brandizzi and Barlowe, 2013; Di Sansebastiano, 2013; Singh and Jürgens, 2018).

\section{RAB PROTEINS}

The Rab GTPase was one of the first elements involved in vesicle trafficking to be characterised (Gallwitz et al., 1983; Schmitt et al., 1986; Goud et al., 1990). First identified in yeast and called Ypt, their animal counterpart was found by 
complementation approaches with cDNA isolated from rat brain (Touchot et al., 1987). During vesicular trafficking, Rab usually acts in targeting and/or tethering of transport vesicles to an acceptor membrane. A complex set of proteins functions to maintain the equilibrium between the active GTP-bound form and an inactive GDPbound form of Rab. After a brief explanation of how Rabs are activated/inactivated and targeted to the membrane, we will further discuss their function in plant membrane trafficking.

\section{Rab Prenylation}

When associated with GTP, Rab typically binds to membranes through prenylation of its C-terminus. The Rab geranylgeranyl transferases (RGGT) are required for Rab prenylation in plants. They work as heterodimers of alpha and beta subunits. To be efficiently prenylated by RGGT, Rab needs to be in a complex with the Rab Escort Protein (REP), as it was demonstrated for RabA2a (Hála et al., 2005; Wojtas et al., 2007; Shi et al., 2016) (Figure1). In the absence of AtREP1, the Arabidopsis RGGT can prenylate other substrates, like Rho GTPases or G-proteins (Shi et al., 2016).

\section{Going Apart with GDI}

When Rabs are in their inactive, GDP-bound state, they dissociate from the membrane and are retained in the cytoplasm through the action of GDI proteins (GDP dissociation inhibitor) that mask their geranylgeranyl moiety (Figure1). Two isoforms of GDI are expressed in Arabidopsis vegetative tissues. They both interact with RabA5c and were shown to complement the defective yeast mutant sec19/gdi1, suggesting that they have a conserved function (Ueda et al., 1996; Andreeva et al., 1997; Ueda et al., 1998). A third isoform of GDI present in the Arabidopsis genome is 
predominantly expressed in pollen, ovules, and embryos suggesting that it has an activity related to reproduction and the early stages of plant development.

\section{Coming Back to the Membrane}

To execute their function, Rabs have to dissociate from GDI and travel to the appropriate membrane. This is achieved by the GDI displacement factor (GDF), PRA1/YIP belongs to this family (Figure1).

In Arabidopsis, 19 small membrane proteins grouped in 8 clades display sequence homology to animal or yeast PRA1/YIP (Kamei et al., 2008). Depending on the isoform, these membrane proteins can localise to all membranes in the secretory pathway, from the ER and Golgi to the TGN (trans Golgi network)/early endosomes and PVC (pre-vacuolar compartment) (Kamei et al., 2008). It was demonstrated that a unique PRA1/YIP isoform in rice, which interacts with OsRab7, is required for vesicular trafficking toward the vacuole (Heo et al., 2010). Also, the overexpression and RNAi approach demonstrated that AtPRA1.B6 regulates ER anterograde trafficking, perturbing post Golgi trafficking (Lee et al., 2011). Another isoform of PRA1/YIP, AtPRA1F4, is localized at the Golgi and participates in the sorting of cargo proteins to the TGN (Lee et al., 2011).

More recently, the YIP4a and $b$ were shown to be associated with ECHIDNA at the TGN, suggesting that they may participate in PM sorting of specific cargo like AUX1 (Gendre et al., 2013; Gendre et al., 2019). The role of YIP4a and b on exocytotic routing could also be estimated since they interact with the Golgi localized RABH1b (Renna et al., 2018). Indeed, rabh1b shows a defect in CESA6 distribution and velocity at the PM. This default was associated with a slowdown of CESA6 trafficking 
to the PM together with a thinner cell wall and a reduction in the growth of etiolated hypocotyls (He et al., 2018).

\section{Rab Inactivation and Activation}

As with many small GTPases, Rabs by themselves only have a weak GTPase activity. To be "turned off" by putting them back in their GDP-bound forms, they need the help of accessory proteins called GTPase-activating proteins (GAP) to hydrolyze GTP. In Arabidopsis, 20 genes show RabGAP catalytic core motifs and contain a conserved Arg residue critical for RabGAP activity, but the exact physiological role of the RabGAP proteins in plants remains mostly elusive (Albert et al., 1999; Vernoud et al., 2003).

After being associated with the appropriate membrane, Rabs can be converted to their activated form by RabGEF (Guanine nucleotide Exchange Factor) proteins. They mediate the exchange of GDP to GTP, allowing a conformational change of Rabs and ultimately affecting their interaction with effector proteins. AtVPS9a and b are the only genes containing a typical RabGEF domain in the Arabidopsis genome, suggesting a weak specificity of interaction between Rabs and RabGEFs (Saito and Ueda, 2009). This was illustrated by Goh et al., who demonstrated that VSP9a mediates the activation of RabF1, RabF2a, RabF2b but not RabG3f (Goh et al., 2007). The interaction of the VPS9a and RabF2b complex was resolved by crystallography and it was shown that the leaky allele vps9a-2 could be rescued by the dominant active Q92L form of RabF2b (Goh et al., 2007; Uejima et al., 2010). This suggests that VPS9a acts upstream of RabF. In addition to the VPS9s, other 
types of proteins that do not contain the typical RabGEF domain can participate directly or indirectly in Rab activation. For instance, PUF2 was shown to recruit VSP9a in the endosomal membrane and coordinates the activation of RabF2b and RabF1 (Ito et al., 2018a). Also, some proteins were suggested to have a GEF activity. Loss of TGN (LOT) displays a substantial homology with the yeast Rgp1 (Jia et al., 2018). RGP1 was suggested to act as a functional RabGEF for the yeast YPT6 and the animal Rab6 (Siniossoglou et al., 2000; Bonifacino and Rojas, 2006). The authors show that LOT cDNA was able to complement yeast rgp1, and that loss of function plants have massive defects in Golgi and TGN structure. These results suggest that LOT may act as a RabGEF protein in plants (Jia et al., 2018). GEF activity toward Rab proteins can also be mediated by tethering complexes. It is most prominently the case in yeast and animal cells through the transport protein particle (TRAPP) complex (Barrowman et al., 2010; Vukašinović and Žárský, 2016). In yeast, four forms of TRAPP complexes are described, where TRAPPI acts as a tethering factor for COPII derived vesicles, TRAPPII and TRAPPIII are involved in post Golgi trafficking and TRAPPIII and TRAPPIV in autophagy (Barrowman et al., 2010). More recently, this model has been challenged, and it was concluded that yeast may only possess TRAPPII and TRAPPIII complexes as in mammalian cells (Thomas et al., 2018). In plants, TRS130, one element of the TRAPPII complex, and RabA1c were found to co-localize at the TGN (Qi and Zheng, 2011). Overexpression of GTP-locked Q72L RabA1c was able to partially complement the trs130 loss of function mutant, suggesting that TRAPPII is an upstream activator of Rabs in plants (Qi and Zheng, 2011). More recently, Rabs of several clades (E, D, B, A, and G) were identified in a TRS130 interactome and several elements of the TRAPPII complex, including TRS130, demonstrate a preferential binding with the dominant-negative S26N 
RabA2a. In addition, a GTP locked Rab variant can complement a trappii mutant (Kalde et al., 2019). These results illustrate the ability of the plant TRAPPII complex to activate Rab proteins. The STOMATAL CYTOKINESIS DEFECTIVE1 (SCD1) contains a tripartite DENN domain that has been demonstrated in other systems to function as GEF for Rab GTPases (Marat et al., 2011). SCD1 acts on the exocyst complex and loss of function plants display perturbations of protein exocytosis and recycling of PM proteins like PIN1 (Mayers et al., 2017). SCD1 interacts preferentially with Rabs from the clade E and in a nucleotide state manner. Indeed, SCD1 interacts in vitro with a dominant negative form S29N, but not with a constitutively active form of RabE1c (Q74L). Mayer et al show that overexpression of wild type or Q74L RabE1c can rescue the phenotype of scd1.1. Consequently, it was postulated that SCD1 acts as a GEF to mediate RadE1c activation during the process of exocytosis.

\section{RAB Complexes Talk with Effector Proteins}

In their GTP-bound form, Rabs interact with effector proteins. Compared to the huge number of Rab isoforms in plants, only a few effectors have been characterized. A portion of them act as tethering factors and participate in the docking of vesicles to acceptor membranes. This is especially true in the case of Golgins, which are long coiled-coil proteins located at the surface of Golgi stacks. Six Golgin homologs were identified in the Arabidopsis genome and at least one, GC5, shares homology with the yeast Sgm1p and was shown to interact with RabH1b and RabH1c (Latijnhouwers et al., 2007).

Other well-described effectors of Rabs are phosphoinositide kinases and phosphatases. Indeed, the PI4KBeta1 and beta2 localise at the TGN and interact with the constitutively active form of RabA4b, Q68L, but not the dominant-negative 
T22N form. This interaction contributes to the polarised secretion of cell wall components in tip-growing cells, but is also important in biotic interactions (Preuss et al., 2006; Kang et al., 2011; Antignani et al., 2015).

All five members of the Rab clade $E$ were shown to interact with the phosphatidylinositol-4-phosphate 5-kinase 2 (PIP5K2). In addition, it was shown that PIP5K2 has a greater affinity for the GTP locked form of Rabs. Therefore, it seems that RabE may be able to regulate PIP5K2, most likely through protein retargeting (Camacho et al., 2009). It was also shown that the PI4P phosphatase Root Hair Defective 4 (RHD4) is required for the proper localisation of the RabA4b (Thole et al., 2008). Therefore, PI4P regulation at the tip of growing cells is a direct target of Rab GTPases and illustrates that the function of Rab effectors is not restricted to tethering factors involved in vesicle fusion.

\section{FUNCTIONAL ROLE OF RAB PROTEINS IN PLANTS}

In plants, Rabs are divided into 8 clades based on their sequence homology, which correlates to some extent to their subcellular localisation and function (Vernoud et al., 2003) (Figure 2).

\section{Rabs in ER-Golgi / Golgi-ER Trafficking}

ER-Golgi trafficking mostly involves Rabs from the clades B1 and D. Specifically in Arabidopsis, ER-Golgi trafficking is thought to involve at least three isoforms of RabB1. Indeed, some of the plant Rab1 isoforms were shown to complement the yeast Rab1 homolog, Ypt1 (Park et al., 1994). Furthermore, the expression of a dominant-negative version of RabB1b in tobacco leaves slows down the recovery of Golgi fluorescence, in BFA (brefeldin A) treated cells. This indicates a role for the 
Rab clade B1 in ER-Golgi anterograde transport (Saint-Jore et al., 2002). RabDs are

Golgi localized and Arabidopsis loss-of-function mutants of the three isoforms show a bushy phenotype and low fertility. Interestingly, by using a dominant-negative approach it was possible to show that RabD1 and D2 are both needed for protein targeting, but most likely function in two independent pathways (Pinheiro et al., 2009).

The Rab clade $\mathrm{H}$ is also involved in ER-Golgi trafficking. Members of the Rab clade $\mathrm{H}$ are homologous to Rab6 andYpt6, identified in animal and yeast cells respectively. RabHs are typically cis-Golgi resident and are described as being involved in Golgi to ER retrograde transport. There is some evidence of a conservation in protein function of RabHs across different phyla as RabH1b can functionally complement the yeast homolog Ypt6 (Bednarek et al., 1994). RabH1b and c were also reported to localise to the Golgi and to interact with Golgins, putative Golgi tether proteins (Latijnhouwers et al., 2007; Johansen et al., 2009). RabH1b was also shown to participate in an anterograde trafficking route from the Golgi, as its expression was necessary for CESA6 localisation at the PM (He et al., 2018). Identification of the exact role of Rab clade $\mathrm{H}$ in retrograde trafficking in plants warrants further investigation.

\section{Rabs in post-Golgi Trafficking to the PM and Cell Plate}

In plants, Rab proteins from clade $\mathrm{E}$ regulate trafficking at or after the Golgi. The expression of a dominant-negative inactive form of RabE1d (N128I) results in an accumulation of sec-GFP in the ER and Golgi; and induces the re-localisation of the sec-GFP signal to the vacuole (Zheng et al., 2005). In this study, the authors also demonstrate that RabE1d is acting downstream of RabD2. YFP-tagged RabE1d was shown to localise at the Golgi in a prenylation and nucleotide-dependent mechanism 
271 (Zheng et al., 2005). Interestingly, the RabE1c was also shown to regulate the 272 localisation and function of the peroxisome receptor PEX7, demonstrating that Rabs 273 from the same clade can have extended functions in plants (Cui et al., 2013). In Arabidopsis, RabA constitutes the biggest clade and contains almost half of the known Rab isoforms. The remarkable expansion of this clade is one of the most striking features of plant Rab GTPases. RabAs are classically associated with postGolgi secretion. The subgroup A1 contains 9 members and clear homologs have not been identified in either yeast or animals. RabA1a, A1b, and A1c are thought to be linked to auxin signaling. RabA1a loss of function mutants show a deficit in auxin response (Koh et al., 2009). When functionally linked to TRAPPII, RabA1c was shown to accumulate in a VHa1 positive TGN compartment (Qi and Zheng, 2011). Its correct localisation is sensitive to the specific inhibitor endosin1 and determines PM targeting of PIN2 and AUX1 (Qi and Zheng, 2013). BEX5/Rab1b, which was identified in a reverse genetic screen for enhanced susceptibility to BFA, participates in both exocytosis and transcytosis of PM proteins including PIN1 and PIN2 (Feraru et al., 2012).

Other Rabs identified in clade A were demonstrated to have a role in cell plate formation. Though RabA1d and 1e typically localize to the TGN, during cell plate formation both instead localise to the cell plate, albeit in a different zone to RabA2a (Berson et al., 2014). Interestingly, RabA1e was also identified as being upregulated in response to salt stress in Arabidopsis roots. This is suggestive of a potential role for this specific isoform during stress acclimation (Geng et al., 2013). In other plant species, the NtRab11b has been demonstrated to play a key role in pollen tube growth. It localizes to the apical clear zone of the elongating pollen tubes and is 
required for secretion and endocytosis at the tip of the pollen tubes (de Graaf et al., 2005).

Subsequently, the role of the tomato Rab11a in secretion has been investigated in tobacco protoplasts. Rehman et al. have suggested that Rab11a can regulate the anterograde transport from the TGN to the PM in a SYP122-dependent manner, and did not involve SYP121, supporting the hypothesis that SYP121 and SYP122 may function in independent secretory events (Rehman et al., 2008). Secretome proteomic analysis of the culture medium surrounding tobacco protoplasts expressing dominant-negative transgenes thereafter revealed a potential specific relationship between Rab11 and SYP122 (Rehman et al., 2011).

The Rab subgroup A2 is somewhat similar to both the mammalian Rab11 and the yeast Ypt31/32. RabA2a, alongside the single Rab isoform of the subclade A3, shows a partial co-localization with both a VHA-a1 positive compartment and the PVC (Chow et al., 2008). Interestingly, RabA2a and RabA3 both also localize at the cell plate, suggesting a putative role in polarized secretion. Interestingly, an additional role for RabA2a in establishing apical polarity in Arabidopsis root tips was recently established through chemical genetic approaches (Li et al., 2017). Subgroup A4 also seems to be involved in polarized secretion. In support of this, Rab4b is found to localize at the tip of root hairs, but only during their growth (Preuss et al., 2004). Its TGN localization was shown to be dependent on actin polymerization and the RabA4b compartment does not co-fractionate with the Qa-SNARE AtSYP41 and the Qc-SNARE AtSYP51, both TGN markers (Preuss et al., 2004). This result underlines that the TGN is a structure composed of a multitude of different membrane types with potentially diverse functions. RabA4b is also tightly associated with PIP2 homeostasis through interactions with several PI4K isoforms and co- 
localises with the PI4P phosphatase (Thole et al., 2008; Kang et al., 2011). The role of RabA4 in tip growth cells is further exemplified by the requirement for functional RabA4d for pollen tube growth (Szumlanski and Nielsen, 2009).

In general, the clade RabA fine-tunes polarised secretion and defines specific membrane subregions for vesicle delivery. RabA5c probably best illustrates this role of the RabA clade. This Rab was found to accumulate just below the PM at each of the 8 corners of plant cells (Kirchhelle et al., 2016). Specific inhibition of RabA5c induces perturbations in the cell geometry of the developing lateral organs (Kirchhelle et al., 2016). This default in anisotropic growth and cytokinesis occurs without disrupting default membrane trafficking. Recently, the same group further demonstrated by genetic, modelling, and pharmacological approaches that microtubules and cellulose anisotropy react to the loss of functional RabA5c in plant cells (Kirchhelle et al., 2019). Finally, we can speculate as to a more general role for Rabs in the regulation of cell wall deposition as many Rabs from the clade A show defects cell wall composition (Lunn et al., 2013).

\section{SNARE PROTEINS}

\section{SNARE HISTORY AND DEFINITION}

SNAP25 (synaptosomal-associated protein of $25 \mathrm{kDa}$ ) was the first SNARE protein discovered (Oyler et al., 1989) and during the intervening years the concept of SNAREs was established and developed by Rothman et al. The N-ethylmaleimidesensitive fusion protein (NSF) factor was identified first, followed by the soluble NSF attachment proteins (SNAPs) which are characterized as critical components of intracellular membrane fusion. Finally, an affinity purification procedure isolated the 
first SNAP receptors (SNAREs) from bovine brain cells (Söllner et al., 1993) and the era of SNAREs had begun!

Initially, the concept of SNARE-mediated transport was centered on the concept that one SNARE was present at the transport vesicle ( $\mathrm{v}$-SNARE, $v$ for vesicles) and one at the acceptor membrane (t-SNARE, $t$ for target). SNAREs were then further divided according to the amino acids present in the hydrophobic heptad repeats in the center of the SNARE domain that engaged in membrane fusion. Using these criteria SNAREs were divided into four groups: Qa- (similar to syntaxin 1), Qb- (similar to the $\mathrm{N}$-terminal half of SNAP25), Qc- (similar to the C-terminal half of SNAP25), and RSNAREs. A functional SNARE complex for membrane fusion was determined to be generally formed from a Qa-Qb-Qc cis-SNARE complex on the target membrane and a R-SNARE (v-SNARE) on the transport vesicle to produce the functional fusion trans-SNARE complex (Fasshauer et al., 1998; Bock et al., 2001; Sutter et al., 2006) but this organization may not be the only one which can function in membrane fusion. The first SNAREs discovered in plants were the syntaxin homologue of a yeast pep12 mutant (Bassham et al., 1995) and the syntaxin-related Qa-SNARE AtSYP111 (KNOLLE) gene product involved in cytokinesis (Lukowitz et al., 1996). Since then, a huge number of plant SNAREs have been discovered and found to be critical players in numerous cellular trafficking pathways. To date, 65 SNAREs have been reported in Arabidopsis (Sanderfoot, 2007; Saito and Ueda, 2009; Kim and Brandizzi, 2012). This high number of SNAREs in Arabidopsis and plants in general, compared to the relatively smaller number (only 21) reported in mammalian cells, highlights the complexity and evolution of the endomembrane trafficking system in plants (Sanderfoot, 2007; Barlow and Dacks, 2018). The following chapters will cover SNAREs as key actors in many cellular processes of plant development. 
A very interesting concept for SNARE regulation emerged from the work of Rothman et al. A novel potential function of SNAREs, called i-SNAREs (for inhibitory or interfering SNAREs) was first described by Varlamov et al. (2004). The principle is that an i-SNARE will inhibit a fusion process by substituting for, or binding to, a subunit of a fusogenic SNARE complex to produce a non-fusogenic complex. Varlamov et al. discovered that certain subunits of the cis-Golgi SNARE complex function as i-SNAREs to inhibit fusion mediated by trans-Golgi SNARE complexes, and reciprocally (Varlamov et al., 2004). In plants, the first possibility of such a regulatory function of SNAREs was suggested by Foresti and coworkers (2006), they observed that the trafficking from the PVC to the lytic vacuole was inhibited by the overexpression of the syntaxin AtSYP21. Subsequently, De Benedictis et al. (2013) demonstrated that the Qc-SNAREs AtSYP51 and AtSYP52 localize to both the TGN and the tonoplast, and further established that they act either as t-SNAREs for membrane fusion when present in the TGN/PVC compartments or as i-SNAREs when accumulated at the tonoplast. A review detailing the main aspects of the i-SNARE concept has been published on plants (Di Sansebastiano, 2013). Recently, Chung et al. (2018) showed that AtMEMB12 overexpression resulted in the accumulation of the antimicrobial protein PR1 (Pathogenesis-Related Gene 1) in intracellular membranes, consistent with AtMEMB12 knockout mutants demonstrating increased resistance to the bacterial pathogen Pst (Pseudomonas syringae pv. tomato), as the absence of AtMEMB12 391 stimulates the exocytosis of PR1 (Zhang et al., 2011; Chung et al., 2018). This is in 392 agreement with the suggestion that AtMEMB12 may be a negative regulator for PR1 secretion. It was proposed that AtMEMB12 could be involved in retrograde trafficking 
from the Golgi back to the ER, and therefore PR1 could be recycled to the ER and not be secreted (Zhang et al., 2011). Chung et al. have then demonstrated that AtBET12 interacts with AtMEMB12 (Chung et al., 2018).

The effect of SNAREs overexpression on PR1 may result either from the titration of critical SNARE partners disrupting SNARE machinery homeostasis or from overexpressed SNAREs acting as an i-SNARE in the early secretory pathway and therefore preventing the secretion of PR1-containing vesicles. Also, the general anterograde transport pathway was not perturbed by AtBET12, suggesting a potential role of AtBET12 in "specifically » regulating pathogenesis-related protein secretion and plant immunity.

Further work will be required to characterize further i-SNARE activity in plants, and determine whether the targeting of non-fusogenic SNAREs to specific compartments could tightly regulate protein trafficking in response to various environmental and stress conditions.

\section{SNARES IN THE SECRETORY PATHWAY}

The involvement of SNAREs at different steps of the secretory pathway (ER-Golgi interface and anterograde/retrograde trafficking, TGN and post-Golgi trafficking, the plasma membrane and cytokinesis) will be discussed alongside new roles and concepts concerning their functions and regulation.

A non-exhaustive distribution of SNAREs in the various compartments of the secretory pathway is given in Figure 3 .

\section{SNAREs in Anterograde ER to Golgi Trafficking}


Compared to other protein families that function within the plant transport machinery, relatively little is known about the involvement of SNAREs at the ER-Golgi interface. The first studies detailing the role of SNAREs in the anterograde transport from the ER to the Golgi were developed through a collaboration between the teams of Dr. P. Moreau and Professor C. Hawes (Chatre et al., 2005). By the heterologous expression of Arabidopsis SNARE proteins in tobacco leaf epidermal cells, the ER/Golgi localisation of the R-SNARE AtSec22 and the Golgi localisation of the QaSNARE AtSYP31 ( AtSed5), the Qb-SNARE AtMemb11 and the Qc-SNARE AtBET11 ( AtBS14a) were identified. Overexpression of these SNAREs and especially the R-SNARE AtSec22 and the Qb-SNARE AtMemb11, resulted in both a Golgi membrane marker (ERD2) and a secretory soluble marker (secYFP) becoming retained in the ER network (Chatre et al., 2005), indicating their involvement in the ER-Golgi anterograde transport. Bubeck et al. (2008) also demonstrated that overexpression of the Qa-SNARE AtSYP31 and the Qb-SNARE AtMemb11 impaired ER to Golgi trafficking. The overexpression-dependent inhibition of the ER to Golgi trafficking of several markers was either due to the titration/trapping of partners of these SNAREs or was a consequence of i-SNARE activity as discussed above.

The co-localization of AtSec22 and the GTPase Sar1 at punctae on the ER membrane is indicative of partial localization of these proteins to ER-export sites (Chatre et al., 2005). Subsequently, it was demonstrated that the loss of the function of AtSec22 leads to the fragmentation of the Golgi in pollen and impaired gametophyte development, and retention in the ER of the plasma membrane syntaxin AtSYP124, demonstrating the critical role of AtSec22 in ER-Golgi trafficking (El-Kasmi et al., 2011). 
442

443

444

445

446

447

448

449

450

451

452

Furthermore, expressing an ER-blocked version of AtSYP31 in transgenic tobacco plants affected plant growth (Melser et al., 2009). Finally, the Qc-SNAREs AtBET11 and AtBET12 could also be required for the polar elongation of pollen tubes and embryo development (Bolaños-Villegas et al., 2015).

\section{The concept of 'Golgi entry core compartment' (GECCO)}

Many questions remain about the dynamics of the ER-Golgi interface and interactions between the ER-export sites and the cis-Golgi, how the stacked cisternae of the Golgi are formed and maintained, and which molecular mechanisms are involved.

In tobacco BY-2 cells treated with BFA, the formation of small punctate structures loaded with proteins originating from the cis-most cisternae of the Golgi were observed. These structures were found adjacent to the ER-export sites, and act as scaffolds for Golgi regeneration after BFA washout (Ito et al., 2012). Then, using SCLIM 3D time-lapse observations (super-resolution confocal live imaging microscopy), it was found that a trans-Golgi marker was transported through this compartment during Golgi regeneration, indicating that the cis-most cisternae of the Golgi receive cargo directly from the ER and likely the ER export sites. This compartment was termed the 'Golgi entry core compartment' (GECCO), and is formed independently of the COPII and COPI machinery, and interestingly resembles the ERGIC (ER-Golgi Intermediate Compartment) identified in mammalian cells (Ito et al., 2018a). In addition, it was found that the Qa-SNARE AtSYP31, a cis-Golgi marker that localises to GECCO upon BFA treatment, is normally resident of the cismost cisternae of the Golgi (Ito et al., 2018b). Therefore, as this SNARE was found to play a role in ER to Golgi trafficking (Chatre et al., 2005; Bubeck et al., 2008), it may 
be possible that its function at the ER-Golgi interface is linked to the molecular mechanisms required for the de novo formation of the first Golgi cisternae.

In the future, as discussed above for the SNARE complexes, it would be of interest to determine which other SNAREs and partners are present in the GECCO to understand further membrane dynamics and cargo trafficking at the ER-Golgi interface.

\section{SNAREs in Retrograde Golgi to ER Trafficking}

Even less is known of the role of SNAREs in retrograde Golgi to ER trafficking. The overexpression of the Qa-SNARE AtSYP81 was found to inhibit both anterograde and retrograde transport between the ER and the Golgi, and its localisation to the subdomains of the ER physically separated from the Golgi suggested that they may correspond to ER import sites (Bubeck et al., 2008).

Furthermore, the Qc-SNARE AtSYP72 is located at punctae in the ER, suggesting a localization that is compatible with a role in retrograde transport (Lerich et al., 2012).

\section{What about SNARE Complexes at the ER-Golgi interface?}

Few attempts have been made to identify putative SNARE complexes at the ERGolgi interface. Tai and Banfield (2001) determined that AtBET11 and AtBET12 could form different complexes in vitro with the yeast ER (Sec22) and Golgi (Bos1, Gos1, Sed5 and YKT6) SNAREs. Sec22, Gos1 and Sed5 (AtSYP31 in Arabidopsis) were the most abundant SNAREs observed in these complexes. However, after attempting interactomics of Qa-SNAREs after immunoprecipitations performed on transgenic plants expressing fluorescent constructs, Fujiwara et al. (2014) were unable to detect SNARE proteins that could interact with the Qa-SNAREs AtSYP31 or AtSYP32, most 
likely due suboptimal expression of the transgenic proteins (Fujiwara et al., 2014). Therefore, identifying the endogenous SNARE complexes involved in trafficking at the ER-Golgi interface might prove challenging.

In addition, nothing has yet been published on putative partners of the Qa-SNARE AtSYP81. SNARE complexes at the ER-Golgi interface require further attention in the future in order to understand the overall dynamics and regulation of protein trafficking at this interface.

\section{ER SNAREs and new aspects of their Regulation and Function}

SNAREs (throughout cells, not those solely localized to the ER) are tail-anchored proteins through their C-terminal hydrophobic domain, and it is only recently that a SNARE, Qc-SNARE AtSYP72, was shown to be integrated into the ER membrane via the GET (Guided Entry of Tail-anchored proteins) system (Srivastava et al., 2017). Xing et al. (2017) have further analyzed some components of the GET (Guided Entry of Tail-anchor) pathway in Arabidopsis, and reduced root hair elongation in detected in defective lines, probably corresponding to reduced amounts of nascent SNAREs, and reduced growth phenotypes in overexpressing lines, suggesting a strong regulatory role of the GET pathway in SNARE biogenesis and cellular homeostasis (Xing et al., 2017).

An interesting discovery is the " unexpected » role of a SNARE in ER interaction with the cytoskeleton. ER streaming and remodelling is highly dependent on membranecytoskeleton interactions, Cao et al. (2016) have identified that Qc-SNARE AtSYP73, bearing actin-binding domains, actively anchors the ER membrane to actin filaments. Loss of AtSYP73 function affects the morphology of the ER network, ER streaming, and plant growth, as is observed for myosin-XI mutants (Cao et al., 2016). 
Finally, of the ER-Golgi SNAREs, the Qb-SNARE AtMemb11 was found to interact with the GDP-bound form of ARF1 in the Golgi (Marais et al., 2015). The disturbance of the anterograde pathway caused by overexpression of AtMemb11 (Chatre et al., 2005; Bubeck et al., 2008) may be either directly related to the role of AtMemb11 in a SNARE complex or indirectly as a result of the titration of Arf1. AtMemb11 (mostly localized at the cis-Golgi cisternae) could, therefore, function both as a SNARE for membrane fusion and as a regulator of Arf1 for modulating the COPI machinery. However, it is not known whether AtMemb11 is a member of a SNARE complex at the cis-Golgi apparatus.

\section{GOLGI/TGN: SNAREs at the Hub of Protein Sorting}

The TGN is a tubular/vesicular organelle that can be considered as the central point for sorting of secretory and vacuolar cargos. Therefore, membrane trafficking is strongly regulated at the TGN which is enriched with several families of SNAREs.

Sanderfoot et al. (2001) have identified a functional separation between the QaSNAREs of the AtSYP4 family, which reside mainly in the trans-Golgi network, and the Qa-SNAREs of the AtSYP2 family, found predominantly in the pre-vacuolar compartment (Sanderfoot et al., 2001). They also found that the Qc-SNARE AtSYP61 is a resident of the TGN and can form complexes with the Qb-SNARE AtVTI12 and either of the Qa-SNAREs: AtSYP41 or AtSYP42. Surprisingly, the interactomics of Qa-SNAREs only revealed the Qa-SNARE AtSYP43 (Fujiwara et al., 2014). In addition, Chen et al. (2005) have determined, by using a liposome fusion assay, that the Qa-SNARE AtSYP41 and the Qc-SNARE AtSYP61 are likely to function in independent vesicle fusion reactions with the Qb-SNARE AtVTI12 (Chen et al., 2005). Chen et al. (2005) also identified that the R-SNARES YKT61 and 
YKT62 are essential for membrane fusion mediated by either the Qa-SNARE

561 isolation and subsequent proteomic analysis of AtSYP61 TGN-derived vesicles 562 (Drakakaki et al., 2012). Drakakaki et al. (2012) were able to identify 145 proteins 563 that were specific to the SYP61 TGN-derived vesicles without contamination by 564 known pre-vacolar markers AtSYP21 or AtSYP51. 
Among the proteins identified, analysis of the AtSYP61 proteome identified numerous proteins that function in cellular transport machinery and cargos of high interest for further analysis:

- The Qa-SNAREs AtSYP41 and AtSYP43, the Qb SNARE VTI12, corroborating possible SYP41/SYP61/VTI12 and SYP43/SYP61/VTI12 SNARE complexes at the TGN as described earlier, but confirmed by interactomics of Qa-SNAREs only for the Qa-SNARE AtSYP43 (Fujiwara et al., 2014). These apparent discrepancies probably just reveal how difficult it is to visualize these protein complexes as a function of the technology used and the nature and developmental stage of the material used...

- The plasma membrane SNAREs such as the Qa-SNARE AtSYP121 (PEN1), the Qb/Qc SNARE AtSNAP33 and the R-SNARE AtVAMP722 were also identified (SNAREs facilitating the secretion of cell wall components to the plasma membrane in response to pathogen attack) together with AtVPS45 and several VSRs (VSR3, VSR4 and VSR7), suggesting that the AtSYP61 compartment is highly involved in segregating the secretory and vacuolar pathways.

- GTPases such as AtRABD2a and AtRABD2b were abundantly present and two YIPs (YPT-interacting proteins) were identified in the AtSYP61 proteome. As already indicated above, YIP4a and YIP4b were demonstrated to be critical trafficking components in ROP-dependent root hair formation (Gendre et al., 2019).

- The AtSYP61 proteome contained a Trs120 homolog, a member of the TRAPPII complex possibly involved in cytokinesis. It also included four orthologs of TRAPPI complex subunits. TRAPPI being associated with ER to Golgi transport, the presence of components of TRAPPI in AtSYP61 vesicles suggests that plant TRAPPI might be involved in vesicle fusion at the TGN rather than in ER to Golgi transport, without excluding the possibility of ER-TGN contacts. 
- Several CESA (Cellulose synthase A) complexes were identified in the SYP61

591 proteome. The analysis with the specific inhibitor endosidin 1 revealed that trafficking 592 of CESA complexes can be TGN dependent. Recently, co-localization of CESA3 and 593 AtSYP61 was found to be enhanced upon CESTRIN (CESA trafficking inhibitors) 594 treatment, corroborating the requirement of the AtSYP61 compartment in CESA complexes trafficking (Worden et al., 2015).

- The SYP61 proteome also contained the protein ECHIDNA. It has been shown that ECHIDNA is required for the TGN-mediated trafficking of the auxin influx carrier AUX1 to the plasma membrane, whereas its involvement in the transport of the auxin influx carrier LAX3 or the auxin efflux carrier PIN3 was minor. Trafficking defects of AUX1 in ech mutants were correlated with perturbation of secretory vesicle formation at the TGN (Boutté et al., 2013).

This AtSYP61/ECHIDNA compartment of the TGN was also shown to be enriched with sphingolipids carrying a-hydroxylated acyl-chains of at least 24 carbon atoms, critical for the polar secretory sorting of the auxin carrier PIN2 to the apical membrane of Arabidopsis root epithelial cells. A disturbance of the tubulo-vesicular structure of the TGN was observed, revealing that, together with the specific proteins identified in the cellular transport machinery, these specific sphingolipids govern the morphology and dynamics of this TGN-subdomain.

The TGN-localized coiled-coil protein TNO1 is a putative tethering factor that interacts with the Qa-SNARE SYP41 and is required for TGN localization of the QcSNARE SYP61. Interestingly, the TGN was disrupted and vesicle formation from the Golgi cisternae was affected in a tno1 mutant, and these defects were rescued by overexpression of either the Qa-SNARE SYP41 or the Qc-SNARE SYP61. These 
614

615

results supported the implication of the tethering factor TNO1 in vesicle fusion at the TGN (Yang et al., 2019).

Finally, SCYL2A/B are clathrin-binding proteins which interact with the Qb-SNAREs AtVTI11 and AtVTI12, and CHC1, supporting the notion that SCYL2A/B proteins are involved in clathrin-mediated vesicle trafficking (Jung et al., 2017). Root hair tiplocalized proteins such as ROP2, RHD2, RABA4B, SYP123, and CSLD3, are critical for proper root hair tip growth, but only CSLD3 was mis-localized in the root hairs of scyl2b mutants, supporting the conclusion that SCYL2B to some extent mediates the tip localization of CSLD3 (Cellulose synthase-like protein D3) in root hairs. Therefore, SCYL2B may act as a component of clathrin-mediated vesicle membrane trafficking that regulates secretory processes mediated by TGN and PVC in the process of root hair tip growth (Jung et al., 2017).

As highlighted by Renna and Brandizzi (2020), the numerous tools developed (reverse genetics, proteomics, chemical inhibitors, super-resolution live-cell imaging) together with lipidomics (Wattelet-Boyer et al., 2016) are now available to unravel the different functions of the TGN, to determine all the key actors and functional machineries in the different subdomains involved in cargo sorting and transport, and finally to investigate the homeostatic regulation of the TGN in various environmental conditions.

\section{SNAREs at the Golgi-released independent TGN (GI-TGN)}

The Golgi-released independent TGN (GI-TGN) is a TGN-derived compartment, released from the Golgi-associated TGN (GA-TGN), which has been only described in plant cells thus far (Kang et al., 2011; Uemura et al., 2014). 
Further work has subsequently revealed a tight association between the GI-TGN and the secretory R-SNAREs AtVAMP721 and AtVAMP722, but to a lesser extent AtVAMP727 (vacuolar pathway) was determined (Uemura et al., 2019). The GI-TGNs were shown to mediate the transport of the R-SNARE AtVAMP721 to the plasma membrane, and the Qa-SNAREs of the AtSYP4 group may be involved in the recycling of AtVAMP721 between the plasma membrane and late endosomes, in addition to the transport from the GA-TGN compartment to the plasma membrane via the GI-TGN compartment, through undetermined mechanisms (Uemura et al., 2019). The GI-TGN is proposed to function as a transit compartment between the Golgi and the plasma membrane, and in this model, the GA-TGN could mature into the GI-TGN and then into secretory vesicles through the increase of the concentration of AtVAMP721-dependent components of the secretory pathway (Uemura et al., 2019).

\section{SNAREs in Plasma Membrane Biogenesis, Cytokinesis, and Symbiosis}

A tremendous amount of research has been performed recently, focused on postGolgi trafficking to the plasma membrane and the implication of SNAREs. These studies have revealed the multitude of SNARE complexes that can be formed and attempts to identify the features linked to the specificity of SNARE functions in constitutive exocytosis, cytokinesis, or innate immunity were reached. As discussed earlier, the possibility that SYP121 and SYP122 drive independent secretory events were proposed (Rehman et al., 2008). Then, Professor G. Jürgens et al. demonstrated that the Qa-SNAREs AtSYP111 and AtSYP121 are not switchable in their respective functions in cytokinesis and innate immunity (Reichardt et al., 2011). In addition, they determined that the Qa-SNARE AtSYP132 could replace the QaSNARE AtSYP111, indicating that AtSYP132 could be more related to membrane 
663

664

665

666

667

668

669

670

671

672

673

674

675

676

677

678

679

680

681

682

683

684

685

686

687

fusion in constitutive exocytosis. The strict specificity observed between the QaSNAREs AtSYP111 and AtSYP121 may suggest the involvement of different (specific) SNARE complexes. In a recent interactomic study of Qa-SNAREs, Fujiwara et al (2014) identified the Qc-SNARE AtSYP71 and the R-SNARE AtVAMP721 as partners of the Qa-SNARE AtSYP121 but unfortunately were not able to elucidate a SNARE interactant for the Qa-SNARE AtSYP111 (Fujiwara et al., 2014). This may be explained by the insufficient expression of this SNARE linked to its normally specific expression during cytokinesis. In addition, they identified several SNAREs for the QaSNARE AtSYP132 (the Qb-SNAREs AtNPSN11 and AtNPSN13, and again the QcSNARE AtSYP71 and the R-SNARE AtVAMP721). Using this approach, Fujiwara et al. also determined that the Qa-SNARE AtSYP122 could interact with the same SNAREs interacting with the Qa-SNARE AtSYP132.

Further studies devoted to understanding the requirement of SNARE complexes and their regulation in cytokinesis revealed several critical points: (i) two distinct complexes (Qa-SNARE AtSYP111/Qb,c-SNARE AtSNAP33/R-SNARE AtVAMP721,722 and Qa-SNARE AtSYP111/Qb-SNARE AtNPSN11/Qc-SNARE SYP71/AtVAMP721,722) were found to associate to drive membrane fusion (EI Kasmi et al., 2013); (ii) cytokinesis still occurs in Qa-SNARE AtSYP111 mutant embryos. Park et al (2018) identified cytokinesis defects in a Qa-SNARE AtSYP132 mutant and defined an additional SNARE complex involving the Qa-SNARE AtSYP132 and the same partners shared with the Qa-SNARE AtSYP111, with overlapping and non-overlapping functions of these two complexes (Park et al., 2018); (iii) Karnahl et al (2018) have evidenced that the Sec1/Munc18 (SM) regulatory proteins of SNARE complexes AtSEC11/KEULE (Karnik et al., 2015; Karnahl et al., 2018; Zhang et al., 2019) and its paralog AtSEC1B are respectively 
688

689

690

691

692

693

694

695

696

697

698

699

700

701

702

703

704

705

706

707

708

709

710

711

712

predominantly involved in cytokinesis and secretion regulation; (iv) Interestingly, it was determined that after stopping vesicle formation at the TGN, cis-SNARE complexes were found to accumulate in the early secretory pathway, strongly suggesting that these inactive cis-SNARE complexes are already formed in the ER and transferred as such to the plasma membrane for better efficiency of cytokinesis and directional growth (Karnahl et al., 2017).

Pollen tube growth requires the action of several SNAREs. Three Qa-SNAREs (AtSYP124, AtSYP125 and AtSYP131) are considered as pollen-specific. Slane et al (2017) have shown that they can have overlapping functions in pollen development since only the triple mutant presented a strong gametophytic defect (Slane et al., 2017). This result supports a functional redundancy within members of a given SNARE gene family but a functional specificity of its members has not to been ruledout. Although Silva et al (2010) determined that syntaxins alone do not provide the level of specificity required for apical growth, they have identified a specific distribution of SYP124 mediating an exocytic flow occurring in the flanks of the pollen tube apex and that the syntaxins of the SYP1 family have a different distribution in the pollen tube.

Interestingly, Li et al (2019) have discovered a Tomosyn protein that can bind, through its C-terminal R-SNARE like motif several Qa-SNAREs, and act as a negative regulator of secretion to control pollen development (Li et al., 2019).

Lastly, Pan et al (2016) have discovered an unexpected maturation of the gene of the Qa-SNARE SYP132 in Medicago trunculata (Pan et al., 2016). Effectively, it has been shown that it undergoes alternative cleavage and polyadenylation during the transcription process, which produces two isoforms of the SNARE: MtSYP132A (A for alternative) and MtSYP132C (C for canonical). MtSYP132A is localised to the 
symbiosome membrane and participates in the maturation of symbiosomes, whereas MtSYP132C is the major form in non-nodulated roots and is involved in classical secretory functions, unrelated to symbiosis. They concluded that the presence of SYP132A in angiosperms strongly correlates with the establishment of arbuscular mycorrhizal symbiosis.

SNAREs and other protein families are largely involved in plant cell-microbe interactions (Nathalie Leborgne-Castel and Bouhidel, 2014). A massive remodeling of the host cell PM is required for the formation, and maintenance, of a perimicrobial membrane which will have a unique protein composition and therefore identity. Challenges for the future will be to identify the trafficking pathways and machineries involved in the different types of interactions, and to determine how pathogens affect the protein composition of the host cell PM and consequently plant defense/immunity (Nathalie Leborgne-Castel and Bouhidel, 2014).

\section{SNAREs in Ion Transport Regulation}

Years ago, Professor M. Blatt et al. established a link between the Qa-SNARE AtSYP121, the plasma membrane KAT1 $\mathrm{K}^{+}$-channel activity, and stomatal control (Eisenach et al., 2012). Grefen et al (2015) have further evidenced that the QaSNARE AtSYP121 interacts with a specific domain of KAT1 (the voltage sensor domain) which confers a voltage-dependent control of secretion (Grefen et al., 2015). In addition, Zhang et al $(2015,2017)$ discovered that the R-SNARE AtVAMP721 also interacts with $\mathrm{KAT1}$ but also with another $\mathrm{K}^{+}$-channel, $\mathrm{KC} 1$, indicating a tight regulation between the $\mathrm{K}^{+}$-channels and the AtSYP121/AtVAMP721 SNARE complex (Zhang et al., 2015; Zhang et al., 2017). Finally, Waghmare et al (2019) determined that the Qb,c-SNARE AtSNAP33 stabilizes the AtSYP121/AtVAMP721 SNARE 
complex after priming of the Qa-SNARE AtSYP121, through its interaction with $\mathrm{K}^{+}$channel (Waghmare et al., 2019). It was suggested that this binding could correspond to a primary state for the initiation of the secretory/fusion machinery for exocytosis.

Although the single mutants of AtSYP121 and AtSYP122 did not show any phenotype, revealing a high redundancy, Waghmare et al (2018) have identified some cargos specific for both SNAREs through a proteomic approach, suggesting that each Qa-SNARE may be engaged to some extent in different pathways according to the nature of some cargos (Waghmare et al., 2018). It has been demonstrated previously that the Qa-SNARE AtSYP121 is involved in the delivery of the aquaporin PIP2;5 in maize and the aquaporin PIP2;7 in Arabidopsis to the plasma membrane, implying this SNARE functions in the regulation of plasma membrane water permeability and cell osmotic homeostasis (Besserer et al., 2012; Hachez et al., 2014). Water and nutrient uptake in root hairs has been shown to involve the Qa-SNAREs AtSYP123 and AtSYP132 which interact with the R-SNAREs AtVAMP721,722,724 at the tip (Ichikawa et al., 2014). The Qa-SNARE AtSYP132 was also found to regulate the transport of and as a consequence the activity of $\mathrm{H}^{+}$ATPase at the plasma membrane and this in an auxin-dependent manner (Xia et al., 2019). Modulation of plasma membrane $H^{+}$-ATPases AHA1 and AHA2 activities were found to involve the R-SNARE AtVAMP711 during drought stress since its deletion increased $\mathrm{H}^{+}$-ATPase activity and slowed down stomatal closure in response to both abscisic acid and drought treatments (Xue et al., 2018).

\section{SNAREs in Pathogen Defense}


762

763

Another interesting feature is how pathogens differently take over the host early secretory pathway for their own purposes, as illustrated by the following examples.

The pathogen Colletotrichum orbiculare develops hyphae inside the host cucumber (Cucumis sativus) by using the CsSec22-dependent secretory pathway to secrete biotrophy effectors toward the interface between the pathogen and the host (Irieda et al., 2014). On the contrary, during the infection of tobacco (Nicotiana benthamiana) by the Turnip mosaic virus, overexpression of the R-SNARE NbSec22 blocked the early secretory pathway but enhanced the movement of replication vesicles, indicating that these vesicles bypassed the Golgi and used an alternative route (prevacuolar/multi-vesicular bodies) for virus propagation (Cabanillas et al., 2018).

Recently, Sasvary et al (2018) have studied the replication of the Tomato bushy stunt virus (TBSV) in tobacco and yeast (Sasvari et al., 2018). They have found in yeast that the viral replication protein $p 33$ can interact with Use1p, the syntaxin Ufe1p and its plant ortholog AtSyp81. In tobacco, the replication of TBSV RNA had an efficiency of only $25 \%$ in the NbSYP81 knockdown plants whereas that of the Tobacco mosaic virus had an efficiency of $70 \%$, suggesting that SYP81 (required for retrograde protein transport in plants) was to some extent specifically required for tombusvirus RNA replication and accumulation in plants, but the retrograde transport pathway was shown not to be required in yeast.

Finally, they could propose in yeast a model on an assembly hub role of the yeast Ufe1 and Use1 SNARE proteins at specific subdomains of the ER for the formation of the TBSV replication compartment (Sasvari et al., 2018). Such a model with SYP81 and other SNAREs/partners may also be functional in plant cells.

Through investigation of the powdery mildew fungus pathogen Blumeria graminis $\mathrm{f}$. sp. hordei, and after reconstruction of 3-D images, Uemura et al. (2019) showed that 
the Qa-SNARE AtSYP43 and the R-SNARE AtVAMP721 accumulated at specific sites of fungal ingress. It was also shown that the Qa-SNAREs of AtSYP4 group and the R-SNARE VAMP721 are involved in the secretion of cell wall-modification enzymes, which are known to be crucial for plant growth and pathogen defense.

Plasma membrane SNAREs are also known to be critical for pathogen defense. The Qa-SNARE AtSYP121 (PEN1), the Qb/Qc SNARE AtSNAP33 and the R-SNARE AtVAMP721/722 are involved in the response to ascomycete and oomycete pathogens. Yun et al (2013) have shown that the infected plant prioritizes the use of the R-SNARE AtVAMP721/722 and partners for secretion linked to the defense pathway instead of secretion linked to plant growth (Yun et al., 2013). Kim et al (2014) have shown that the powdery mildew resistance protein RPW8.2 is transported to the plant-fungal interface through AtVAMP721 vesicles and that defense is highly decreased in the absence of this R-SNARE (Kim et al., 2014).

It was then shown that synaptotagmin 1 deletion increased the resistance to the pathogen Golovinomyces orontii, and that the fungus induced interactions between the Qa-SNARE AtSYP121 and synaptotagmin 1 and inhibition of the formation of the AtSYP121 SNARE complex (Kim et al., 2016).

Brassinosteroid-induced genes control several aspects of plant development and especially stress and pathogen response. It was proposed that the SNARE complex containing the Qa-SNARE AtSYP22 and the R-SNARE AtVAMP727 drives the transport to the plasma membrane of the brassinosteroid receptor BRI1 (Zhang et al 2019), and regulates plant resistance to pathogens by controlling the amount of BRI1 reaching/accumulating at the plasma membrane (Zhu et al., 2019). Cao et al (2019) have also shown in rice that the Qa-SNARE OsSYP121 accumulates at pathogen penetration sites can interact with the Qb,c-SNARE OsSNAP32 and the R-SNARE 
OsVAMP714/724 and contributes to host resistance to rice blast induced by the fungal pathogen Magnaporthe oryzae (Cao et al., 2019).

Finally, lipid signaling through phospholipase $D \delta$ has been found to regulate plant innate immunity (Xing et al., 2019). Following pathogen attack, it was shown that the phospholipase D $\delta$ is secreted via an AtVAMP721/722-mediated secretory process and led to a focused production of phosphatidic acid which activates reactive oxygen species and jasmonic acid signaling pathways (Xing et al., 2019). Therefore, we can imagine how many molecular interactions and different levels of regulation we still have to discover to understand all these mechanisms...

\section{CONCLUSIONS AND EXPECTATIONS FOR THE FUTURE...}

A first important conclusion concerning Rabs and SNAREs is the multi-combinatorial possibilities and specificities which are offered by the number of actors that evolution produced for both protein families. This originates, of course, from the increased needs of devoted machineries to many aspects of plant development and plant responses to their environment.

At the molecular and mechanistic level, this effectively implies a multitude of protein interactions, of regulation steps, signaling pathways, without excluding the lipid partners. Regarding SNAREs, more and more interactants are discovered such as QUIRKY (a member of the MCTP protein family having multiple C2 domains and transmembrane domains) which has recently been shown to interact with the QaSNARE AtSYP121 to sustain florigen transport in Arabidopsis (Liu et al., 2019).

In the case of Rab proteins, the high number of isoforms must be associated with the complexity of secretion processes in plants and especially regarding post Golgi 
trafficking as it is highlighted in the recent review by Elliott et al. (2020). In addition, Rabs are also surrounded by many regulating partners. For example, 20 RabGAP and 19 PRA1 isoforms are present in the Arabidopsis genome. They are respectively involved in Rab inactivation and Rab membrane targeting. As a consequence, it would be particularly challenging to describe the combinatorial interactions that must exist in cells on a one by one basis. New interactomic approaches that rely on proximity labelling may be used to shed light on this complexity in plants (Del Olmo et al., 2019; Gillingham et al., 2019).

Furthermore, the development of optogenetic approaches offers new avenues to bypass the genetic plasticity often observed with Rab knock out or overexpressor lines. Indeed, optogenetically controlled oligomerisation was used to inactivate Rab function in cells within minutes (Nguyen et al., 2016). These approaches are promising for plant Rab biology and will help to further understand their precise function in development or plant defense (Banerjee and Mitra, 2020).

Moreover, the involvement of many protein families (tethering factors, SNAREs, small GTPases, adaptor proteins, ECHIDNA and so forth) in Golgi-plasma membrane (and vacuolar) trafficking pathways highlights the requirement for a multiplicity of GI-TGN subdomains and derived transport vesicles which must be engaged in numerous transport pathways for numerous different cargos. A recent example is given by De Caroli et al. (2020) on CesA6 and PGIP2 trafficking involving distinct subpopulations of TGN-related endosomes.

The challenge for the future will therefore be to identify the respective protein assemblies and to decipher the corresponding molecular mechanisms and their regulation, which are associated with each potential pathway in this huge network of membranes/organelles exchanges. 
861

Finally, a new protein family may also deserve our future attention, the proteins which

862 have been called phytolongins and correspond to non-SNARE longins. Phytolongins

863 contain a typical SNARE-like longin domain but lack the central SNARE domain (for

864 membrane fusion) which is replaced by a "PhyL domain" of unknown function, and 865

866

867

868

869

870

871

872

873

874 the 4 proteins of this family are located along the secretory pathway: Phyl2.1 and Phy2.2 in the ER, Phyl1.2 in the Golgi, Phyl1.1 at the plasma membrane and to a lesser extent in post-Golgi compartments (de Marcos Lousa et al., 2016). These proteins, according to their cellular location and the absence of a « fusion domain », could regulate the SNARE complexes by interacting through their longin domain, could be involved in ER and Golgi structure, could participate along the secretory pathway and at the cell surface to plant responses to various stimuli.

\section{Acknowledgments}

Of course the review, as this special issue, is devoted to the memory of Professor Chris Hawes, both as a brilliant scientist and a very good friend.

To initiate the investigation of SNAREs at the ER-Golgi interface, P. Moreau and C. Hawes were the recipients of a Franco-British Research Partnership Program Alliance (Egide/British Council) 2002-2004. P. Moreau also wants to thank L. Chatre and F. Brandizzi for all the work which has been performed together on SNAREs. P. Moreau thanks $\mathrm{C}$. Marais (PhD fellow from the Ministère de l'Enseignement Supérieur et de la Recherche) for the work on Memb11, and all the colleagues of the lab who participated to some extent to the work of the team on SNAREs. P. Moreau also thanks Professor F. Filippini and Dr C. de Marcos-Lousa for their fruitful collaboration on phytolongins. 
The financial support of CNRS and University of Bordeaux to PM for all of these years is fully acknowledged. AM is funded by the French National Research Agency ANR CellOsmo (ANR-19-CE20-0008-01).

We warmly thank $\mathrm{Dr}$ B. Satiat-Jeunemaitre for her critical and supportive reading of our manuscript, the reviewers for their contribution to improving the review and Charlotte Pain and Stefan Wojcik for having read and corrected the English.

\section{Legends to Figures}

Figure 1: Schematic diagram of Rab cycle.

(i) Rab becomes prenylated at their $\mathrm{C}$-terminus by an association between the Rab GeranylGeranyl Transferases (RGGT) and the Rab Escort Protein (REP). Before reaching the target vesicle, Rab is maintained in the cytoplasm through the action of REP to mask the Rab geranylgeranyl moiety. (ii) Membrane association is mediated by GDI displacement factor (GDF) belonging to the family of PRA1/YIP. REP protein or GDI protein are removed and Rab prenylated tail is inserted into the vesicle bilayer. (iii) Upon trigger, GDP/GTP exchange factors (GEF) mediate Rab conformation change. Once activated, Rab interacts with effector proteins such as tethering factors needed for vesicle docking with acceptor membrane. (iv) Rab inactivation is achieved by GTPase-activating proteins (GAP). They help Rab to hydrolyse GTP and turn them back to their inactive conformation. Then, Rab dissociate from the membrane and form a cytoplasmic complex with GDI proteins.

\section{Figure 2: Localisation of the different clades of Rab involved in secretion.} Rab $B$ and D are associated with ER to Golgi anterograde trafficking. Rab H participates to retrograde trafficking. Rab $A$ and $E$ are involved in the post Golgi trafficking.

ER: Endoplasmic reticulum, ERES: Endoplasmic reticulum exist site, GA-TGN: Golgi associated trans Golgi network, GI-TGN: Golgi independent trans Golgi network, PM: plasma membrane.

\section{Figure 3: Localisation of the different SNAREs involved in secretion or other} functions.

In blue SNAREs exclusively or mainly associated with the ER, in green SNAREs located in the Golgi and for some of them involved in ER-Golgi exchanges. In orange SNAREs located at the TGN compartments and are involved in different 
steps/aspects of post Golgi trafficking. In red, SNAREs either present at the plasma membrane and/or engaged in trafficking to this membrane (SYP71 can have a duallocation between the ER and the PM, Suwastika et al., 2008).

For details on their location and functions, please refer to the text in the different chapters.

ER: Endoplasmic reticulum, ERES: Endoplasmic reticulum exist site, GA-TGN: Golgi associated trans Golgi network, GI-TGN: Golgi independent trans Golgi network, PM: plasma membrane.

\section{REFERENCES}

Albert S, Will E, Gallwitz D (1999) Identification of the catalytic domains and their functionally critical arginine residues of two yeast GTPase-activating proteins specific for Ypt/Rab transport GTPases. EMBO J 18: 5216-5225

Andreeva AV, Kutuzov MA, Evans DE, Hawes CR (1997) Rab-GDP dissociation inhibitor isoforms in Arabidopsis thaliana. J Exp Bot 48: 2109-2110

Antignani V, Klocko AL, Bak G, Chandrasekaran SD, Dunivin T, Nielsen E (2015) Recruitment of PLANT U-BOX13 and the PI4K $\beta 1 / \beta 2$ phosphatidylinositol-4 kinases by the small GTPase RabA4B plays important roles during salicylic acid-mediated plant defense signaling in Arabidopsis. Plant Cell 27: 243-261

Banerjee S, Mitra D (2020) Structural Basis of Design and Engineering for Advanced Plant Optogenetics. Trends Plant Sci 25: 35-65

Barlow LD, Dacks JB (2018) Seeing the endomembrane system for the trees: Evolutionary analysis highlights the importance of plants as models for eukaryotic membrane-trafficking. Semin Cell Dev Biol 80: 142-152

Barrowman J, Bhandari D, Reinisch KM, Ferro-Novick S (2010) TRAPP complexes in membrane traffic: convergence through a common Rab. Nat Rev Mol Cell Biol. doi: 10.1038/nrm2999

Bassham DC, Gal S, da Silva Conceição A, Raikhel NV (1995) An Arabidopsis syntaxin homologue isolated by functional complementation of a yeast pep12 mutant. Proc Natl Acad Sci U S A 92: 7262-7266

Bednarek SY, Reynolds TL, Schroeder M, Grabowski R, Hengst L, Gallwitz D, Raikhel NV (1994) A small GTP-binding protein from Arabidopsis thaliana functionally complements the yeast YPT6 null mutant. Plant Physiol 104: 591-596

Berson T, von Wangenheim D, Takáč T, Šamajová O, Rosero A, Ovečka M, Komis G, Stelzer EH, Šamaj J (2014) Trans-Golgi network localized small GTPase RabA1d is involved in cell plate formation and oscillatory root hair growth. BMC Plant Biol. doi: 10.1186/s12870-014-0252-0

Besserer A, Burnotte E, Bienert GP, Chevalier AS, Errachid A, Grefen C, Blatt MR, Chaumont F (2012) Selective regulation of maize plasma membrane aquaporin trafficking and activity by the SNARE SYP121. Plant Cell 24: 3463-3481 
Bock JB, Matern HT, Peden AA, Scheller RH (2001) A genomic perspective on membrane compartment organization. Nature 409: 839-841

Boevink P, Oparka K, Santa Cruz S, Martin B, Betteridge A, Hawes C (1998) Stacks on tracks: the plant Golgi apparatus traffics on an actin/ER network. Plant J Cell Mol Biol 15: 441-447

Bolaños-Villegas P, Guo C-L, Jauh G-Y (2015) Arabidopsis Qc-SNARE genes BET11 and BET12 are required for fertility and pollen tube elongation. Bot Stud 56: 21

Bonifacino JS, Rojas R (2006) Retrograde transport from endosomes to the trans-Golgi network. Nat Rev Mol Cell Biol 7: 568-579

Boutté Y, Jonsson K, McFarlane HE, Johnson E, Gendre D, Swarup R, Friml J, Samuels L, Robert S, Bhalerao RP (2013) ECHIDNA-mediated post-Golgi trafficking of auxin carriers for differential cell elongation. Proc Natl Acad Sci U S A 110: 16259-16264

Brandizzi F, Barlowe C (2013) Organization of the ER-Golgi interface for membrane traffic control. Nat Rev Mol Cell Biol 14: 382-392

Bubeck J, Scheuring D, Hummel E, Langhans M, Viotti C, Foresti O, Denecke J, Banfield DK, Robinson DG (2008) The syntaxins SYP31 and SYP81 control ER-Golgi trafficking in the plant secretory pathway. Traffic Cph Den 9: 1629-1652

Cabanillas DG, Jiang J, Movahed N, Germain H, Yamaji Y, Zheng H, Laliberté J-F (2018) Turnip Mosaic Virus Uses the SNARE Protein VTI11 in an Unconventional Route for Replication Vesicle Trafficking. Plant Cell 30: 2594-2615

Camacho L, Smertenko AP, Pérez-Gómez J, Hussey PJ, Moore I (2009) Arabidopsis Rab-E GTPases exhibit a novel interaction with a plasma-membrane phosphatidylinositol-4-phosphate 5kinase. J Cell Sci 122: 4383-4392

Cao W-L, Yu Y, Li M-Y, Luo J, Wang R-S, Tang H-J, Huang J, Wang J-F, Zhang H-S, Bao YM (2019) OsSYP121 Accumulates at Fungal Penetration Sites and Mediates Host Resistance to Rice Blast. Plant Physiol 179: 1330-1342

Chatre L, Brandizzi F, Hocquellet A, Hawes C, Moreau P (2005) Sec22 and Memb11 are vSNAREs of the anterograde endoplasmic reticulum-Golgi pathway in tobacco leaf epidermal cells. Plant Physiol 139: 1244-1254

Chen Y, Shin Y-K, Bassham DC (2005) YKT6 is a core constituent of membrane fusion machineries at the Arabidopsis trans-Golgi network. J Mol Biol 350: 92-101

Chow C-M, Neto H, Foucart C, Moore I (2008) Rab-A2 and Rab-A3 GTPases define a trans-golgi endosomal membrane domain in Arabidopsis that contributes substantially to the cell plate. Plant Cell 20: $101-123$

Chung KP, Zeng Y, Li Y, Ji C, Xia Y, Jiang L (2018) Signal motif-dependent ER export of the QcSNARE BET12 interacts with MEMB12 and affects PR1 trafficking in Arabidopsis. J Cell Sci. doi: $10.1242 /$ jcs. 202838

Cui S, Fukao Y, Mano S, Yamada K, Hayashi M, Nishimura M (2013) Proteomic analysis reveals 
that the Rab GTPase RabE1c is involved in the degradation of the peroxisomal protein receptor PEX7 (peroxin 7). J Biol Chem 288: 6014-6023

daSilva LLP, Snapp EL, Denecke J, Lippincott-Schwartz J, Hawes C, Brandizzi F (2004) Endoplasmic reticulum export sites and Golgi bodies behave as single mobile secretory units in plant cells. Plant Cell 16: 1753-1771

De Benedictis M, Bleve G, Faraco M, Stigliano E, Grieco F, Piro G, Dalessandro G, Di Sansebastiano GP (2013) AtSYP51/52 functions diverge in the post-Golgi traffic and differently affect vacuolar sorting. Mol Plant 6: 916-930

De Caroli M, Manno E, Perrotta C, De Lorenzo G, Di Sansebastiano G-P, Piro G (2020) CesA6 and PGIP2 Endocytosis Involves Different Subpopulations of TGN-Related Endosomes. Front Plant Sci. doi: $10.3389 /$ fpls.2020.00350

Del Olmo T, Lauzier A, Normandin C, Larcher R, Lecours M, Jean D, Lessard L, Steinberg F, Boisvert F-M, Jean S (2019) APEX2-mediated RAB proximity labeling identifies a role for RAB21 in clathrin-independent cargo sorting. EMBO Rep. doi: 10.15252/embr.201847192

Di Sansebastiano G-P (2013) Defining new SNARE functions: the i-SNARE. Front Plant Sci 4: 99

Drakakaki G, van de Ven W, Pan S, Miao Y, Wang J, Keinath NF, Weatherly B, Jiang L, Schumacher K, Hicks G, et al (2012) Isolation and proteomic analysis of the SYP61 compartment reveal its role in exocytic trafficking in Arabidopsis. Cell Res 22: 413-424

Eisenach C, Chen Z-H, Grefen C, Blatt MR (2012) The trafficking protein SYP121 of Arabidopsis connects programmed stomatal closure and $\mathrm{K}^{+}$channel activity with vegetative growth. Plant $\mathrm{J}$ Cell Mol Biol 69: 241-251

El Kasmi F, Krause C, Hiller U, Stierhof Y-D, Mayer U, Conner L, Kong L, Reichardt I, Sanderfoot AA, Jürgens G (2013) SNARE complexes of different composition jointly mediate membrane fusion in Arabidopsis cytokinesis. Mol Biol Cell 24: 1593-1601

El-Kasmi F, Pacher T, Strompen G, Stierhof Y-D, Müller LM, Koncz C, Mayer U, Jürgens G (2011) Arabidopsis SNARE protein SEC22 is essential for gametophyte development and maintenance of Golgi-stack integrity. Plant J Cell Mol Biol 66: 268-279

Fasshauer D, Sutton RB, Brunger AT, Jahn R (1998) Conserved structural features of the synaptic fusion complex: SNARE proteins reclassified as Q- and R-SNAREs. Proc Natl Acad Sci U S A 95: $15781-15786$

Feraru E, Feraru MI, Asaoka R, Paciorek T, De Rycke R, Tanaka H, Nakano A, Friml J (2012) BEX5/RabA1b regulates trans-Golgi network-to-plasma membrane protein trafficking in Arabidopsis. Plant Cell 24: 3074-3086

Fujiwara M, Uemura T, Ebine K, Nishimori Y, Ueda T, Nakano A, Sato MH, Fukao Y (2014) Interactomics of Qa-SNARE in Arabidopsis thaliana. Plant Cell Physiol 55: 781-789

Gallwitz D, Donath C, Sander C (1983) A yeast gene encoding a protein homologous to the human c-has/bas proto-oncogene product. Nature 306: 704-707 
Gendre D, Baral A, Dang X, Esnay N, Boutté Y, Stanislas T, Vain T, Claverol S, Gustavsson A, Lin D, et al (2019) Rho-of-plant activated root hair formation requires Arabidopsis YIP4a/b gene function. Dev Camb Engl. doi: 10.1242/dev.168559

Gendre D, McFarlane HE, Johnson E, Mouille G, Sjödin A, Oh J, Levesque-Tremblay G, Watanabe Y, Samuels L, Bhalerao RP (2013) Trans-Golgi Network Localized ECHIDNA/Ypt Interacting Protein Complex Is Required for the Secretion of Cell Wall Polysaccharides in Arabidopsis. Plant Cell 25: 2633-2646

Geng Y, Wu R, Wee CW, Xie F, Wei X, Chan PMY, Tham C, Duan L, Dinneny JR (2013) A Spatio-Temporal Understanding of Growth Regulation during the Salt Stress Response in Arabidopsis. Plant Cell 25: 2132-2154

Gillingham AK, Bertram J, Begum F, Munro S (2019) In vivo identification of GTPase interactors by mitochondrial relocalization and proximity biotinylation. eLife. doi: 10.7554/eLife.45916

Goh T, Uchida W, Arakawa S, Ito E, Dainobu T, Ebine K, Takeuchi M, Sato K, Ueda T, Nakano A (2007) VPS9a, the common activator for two distinct types of Rab5 GTPases, is essential for the development of Arabidopsis thaliana. Plant Cell 19: 3504-3515

Goud B, Zahraoui A, Tavitian A, Saraste J (1990) Small GTP-binding protein associated with Golgi cisternae. Nature 345: 553-556

de Graaf BHJ, Cheung AY, Andreyeva T, Levasseur K, Kieliszewski M, Wu H (2005) Rab11 GTPase-regulated membrane trafficking is crucial for tip-focused pollen tube growth in tobacco. Plant Cell 17: 2564-2579

Grefen C, Karnik R, Larson E, Lefoulon C, Wang Y, Waghmare S, Zhang B, Hills A, Blatt MR (2015) A vesicle-trafficking protein commandeers Kv channel voltage sensors for voltage-dependent secretion. Nat Plants 1: 15108

Hachez C, Laloux T, Reinhardt H, Cavez D, Degand H, Grefen C, De Rycke R, Inzé D, Blatt MR, Russinova E, et al (2014) Arabidopsis SNAREs SYP61 and SYP121 coordinate the trafficking of plasma membrane aquaporin PIP2;7 to modulate the cell membrane water permeability. Plant Cell 26: $3132-3147$

Hála M, Eliás M, Zárský V (2005) A specific feature of the angiosperm Rab escort protein (REP) and evolution of the REP/GDI superfamily. J Mol Biol 348: 1299-1313

Heo J, Bang WY, Kim S, Hwang S min, Son Y, Im C, Acharya B, Kim C, Kim SW, Lee B, et al (2010) OsPRA1 plays a significant role in targeting of OsRab7 into the tonoplast via the prevacuolar compartment during vacuolar trafficking in plant cells. Planta 232: 861-71

Ichikawa M, Hirano T, Enami K, Fuselier T, Kato N, Kwon C, Voigt B, Schulze-Lefert P, Baluška F, Sato MH (2014) Syntaxin of plant proteins SYP123 and SYP132 mediate root hair tip growth in Arabidopsis thaliana. Plant Cell Physiol 55: 790-800

Irieda H, Maeda H, Akiyama K, Hagiwara A, Saitoh H, Uemura A, Terauchi R, Takano Y (2014) Colletotrichum orbiculare Secretes Virulence Effectors to a Biotrophic Interface at the Primary Hyphal Neck via Exocytosis Coupled with SEC22-Mediated Traffic. Plant Cell 26: 2265-2281 
Ito E, Ebine K, Choi S-W, Ichinose S, Uemura T, Nakano A, Ueda T (2018a) Integration of two RAB5 groups during endosomal transport in plants. eLife. doi: 10.7554/eLife.34064

Ito Y, Uemura T, Nakano A (2018b) The Golgi entry core compartment functions as a COPIIindependent scaffold for ER-to-Golgi transport in plant cells. J Cell Sci. doi: 10.1242/jcs.203893

Ito Y, Uemura T, Shoda K, Fujimoto M, Ueda T, Nakano A (2012) cis-Golgi proteins accumulate near the ER exit sites and act as the scaffold for Golgi regeneration after brefeldin A treatment in tobacco BY-2 cells. Mol Biol Cell 23: 3203-3214

Jia P-F, Xue Y, Li H-J, Yang W-C (2018) Golgi-localized LOT regulates trans-Golgi network biogenesis and pollen tube growth. Proc Natl Acad Sci 115: 12307-12312

Johansen JN, Chow C-M, Moore I, Hawes C (2009) AtRAB-H1b and AtRAB-H1c GTPases, homologues of the yeast Ypt6, target reporter proteins to the Golgi when expressed in Nicotiana tabacum and Arabidopsis thaliana. J Exp Bot 60: 3179-3193

Jung J-Y, Lee DW, Ryu SB, Hwang I, Schachtman DP (2017) SCYL2 Genes Are Involved in Clathrin-Mediated Vesicle Trafficking and Essential for Plant Growth. Plant Physiol 175: 194-209

Kalde M, Elliott L, Ravikumar R, Rybak K, Altmann M, Klaeger S, Wiese C, Abele M, Al B, Kalbfuß N, et al (2019) Interactions between Transport Protein Particle (TRAPP) complexes and Rab GTPases in Arabidopsis. Plant J Cell Mol Biol 100: 279-297

Kamei CLA, Boruc J, Vandepoele K, Daele HV den, Maes S, Russinova E, Inzé D, Veylder LD (2008) The PRA1 Gene Family in Arabidopsis. Plant Physiol 147: 1735-1749

Kang B-H, Nielsen E, Preuss ML, Mastronarde D, Staehelin LA (2011) Electron tomography of RabA4b- and PI-4K $\beta 1$-labeled trans Golgi network compartments in Arabidopsis. Traffic Cph Den 12: 313-329

Karnahl M, Park M, Krause C, Hiller U, Mayer U, Stierhof Y-D, Jürgens G (2018) Functional diversification of Arabidopsis SEC1-related SM proteins in cytokinetic and secretory membrane fusion. Proc Natl Acad Sci U S A 115: 6309-6314

Karnahl M, Park M, Mayer U, Hiller U, Jürgens G (2017) ER assembly of SNARE complexes mediating formation of partitioning membrane in Arabidopsis cytokinesis. eLife. doi: 10.7554/eLife.25327

Karnik R, Zhang B, Waghmare S, Aderhold C, Grefen C, Blatt MR (2015) Binding of SEC11 indicates its role in SNARE recycling after vesicle fusion and identifies two pathways for vesicular traffic to the plasma membrane. Plant Cell 27: 675-694

Kim H, Kwon H, Kim S, Kim MK, Botella MA, Yun HS, Kwon C (2016) Synaptotagmin 1 Negatively Controls the Two Distinct Immune Secretory Pathways to Powdery Mildew Fungi in Arabidopsis. Plant Cell Physiol 57: 1133-1141

Kim H, O'Connell R, Maekawa-Yoshikawa M, Uemura T, Neumann U, Schulze-Lefert P (2014) The powdery mildew resistance protein RPW8.2 is carried on VAMP721/722 vesicles to the extrahaustorial membrane of haustorial complexes. Plant J Cell Mol Biol 79: 835-847 
Kim S-J, Brandizzi F (2012) News and Views into the SNARE Complexity in Arabidopsis. Front Plant Sci 3: 28

Kirchhelle C, Chow C-M, Foucart C, Neto H, Stierhof Y-D, Kalde M, Walton C, Fricker M, Smith RS, Jérusalem A, et al (2016) The Specification of Geometric Edges by a Plant Rab GTPase Is an Essential Cell-Patterning Principle During Organogenesis in Arabidopsis. Dev Cell 36: 386-400

Kirchhelle C, Garcia-Gonzalez D, Irani NG, Jérusalem A, Moore I Two mechanisms regulate directional cell growth in Arabidopsis lateral roots. eLife. doi: 10.7554/eLife.47988

Koh E-J, Kwon Y-R, Kim K-I, Hong S-W, Lee H (2009) Altered ARA2 (RABA1a) expression in Arabidopsis reveals the involvement of a Rab/YPT family member in auxin-mediated responses. Plant Mol Biol 70: 113-122

Latijnhouwers M, Gillespie T, Boevink P, Kriechbaumer V, Hawes C, Carvalho CM (2007) Localization and domain characterization of Arabidopsis golgin candidates. J Exp Bot 58: 4373-4386

Lee MH, Jung C, Lee J, Kim SY, Lee Y, Hwang I (2011) An Arabidopsis Prenylated Rab Acceptor 1 Isoform, AtPRA1.B6, Displays Differential Inhibitory Effects on Anterograde Trafficking of Proteins at the Endoplasmic Reticulum. Plant Physiol 157: 645-658

Lerich A, Hillmer S, Langhans M, Scheuring D, van Bentum P, Robinson DG (2012) ER Import Sites and Their Relationship to ER Exit Sites: A New Model for Bidirectional ER-Golgi Transport in Higher Plants. Front Plant Sci 3: 143

Li B, Li Y, Liu F, Tan X, Rui Q, Tong Y, Qiao L, Gao R, Li G, Shi R, et al (2019) Overexpressed Tomosyn Binds Syntaxins and Blocks Secretion during Pollen Development. Plant Physiol 181: 11141126

Li R, Rodriguez-Furlan C, Wang J, Ven W van de, Gao T, Raikhel NV, Hicks GR (2017) Different Endomembrane Trafficking Pathways Establish Apical and Basal Polarities. Plant Cell 29: 90-108

Lipka V, Kwon C, Panstruga R (2007) SNARE-ware: the role of SNARE-domain proteins in plant biology. Annu Rev Cell Dev Biol 23: 147-174

Liu L, Li C, Teo ZWN, Zhang B, Yu H (2019) The MCTP-SNARE Complex Regulates Florigen Transport in Arabidopsis. Plant Cell 31: 2475-2490

Lukowitz W, Mayer U, Jürgens G (1996) Cytokinesis in the Arabidopsis embryo involves the syntaxin-related KNOLLE gene product. Cell 84: 61-71

Lunn D, Gaddipati SR, Tucker GA, Lycett GW (2013) Null mutants of individual RABA genes impact the proportion of different cell wall components in stem tissue of Arabidopsis thaliana. PloS One 8: e75724

Marais C, Wattelet-Boyer V, Bouyssou G, Hocquellet A, Dupuy J-W, Batailler B, Brocard L, Boutté Y, Maneta-Peyret L, Moreau P (2015) The Qb-SNARE Memb11 interacts specifically with Arf1 in the Golgi apparatus of Arabidopsis thaliana. J Exp Bot 66: 6665-6678

Marat AL, Dokainish H, McPherson PS (2011) DENN Domain Proteins: Regulators of Rab 
de Marcos Lousa C, Soubeyrand E, Bolognese P, Wattelet-Boyer V, Bouyssou G, Marais C, Boutté Y, Filippini F, Moreau P (2016) Subcellular localization and trafficking of phytolongins (non-SNARE longins) in the plant secretory pathway. J Exp Bot 67: 2627-2639

Mayers JR, Hu T, Wang C, Cárdenas JJ, Tan Y, Pan J, Bednarek SY (2017) SCD1 and SCD2 Form a Complex That Functions with the Exocyst and RabE1 in Exocytosis and Cytokinesis. Plant Cell 29: 2610-2625

Melser S, Wattelet-Boyer V, Brandizzi F, Moreau P (2009) Blocking ER export of the Golgi SNARE SYP31 affects plant growth. Plant Signal Behav 4: 962-964

Moreau P, Brandizzi F, Hanton S, Chatre L, Melser S, Hawes C, Satiat-Jeunemaitre B (2007) The plant ER-Golgi interface: a highly structured and dynamic membrane complex. J Exp Bot 58: 4964

Nathalie Leborgne-Castel null, Bouhidel K (2014) Plasma membrane protein trafficking in plantmicrobe interactions: a plant cell point of view. Front Plant Sci 5: 735

Nguyen MK, Kim CY, Kim JM, Park BO, Lee S, Park H, Heo WD (2016) Optogenetic oligomerization of Rab GTPases regulates intracellular membrane trafficking. Nat Chem Biol 12: $431-436$

Oyler GA, Higgins GA, Hart RA, Battenberg E, Billingsley M, Bloom FE, Wilson MC (1989) The identification of a novel synaptosomal-associated protein, SNAP-25, differentially expressed by neuronal subpopulations. J Cell Biol 109: 3039-3052

Pan H, Oztas O, Zhang X, Wu X, Stonoha C, Wang E, Wang B, Wang D (2016) A symbiotic SNARE protein generated by alternative termination of transcription. Nat Plants 2: 15197

Park M, Krause C, Karnahl M, Reichardt I, El Kasmi F, Mayer U, Stierhof Y-D, Hiller U, Strompen G, Bayer M, et al (2018) Concerted Action of Evolutionarily Ancient and Novel SNARE Complexes in Flowering-Plant Cytokinesis. Dev Cell 44: 500-511.e4

Park YS, Song O, Kwak JM, Hong SW, Lee HH, Nam HG (1994) Functional complementation of a yeast vesicular transport mutation ypt1-1 by a Brassica napus cDNA clone encoding a small GTPbinding protein. Plant Mol Biol 26: 1725-1735

Pinheiro H, Samalova M, Geldner N, Chory J, Martinez A, Moore I (2009) Genetic evidence that the higher plant Rab-D1 and Rab-D2 GTPases exhibit distinct but overlapping interactions in the early secretory pathway. J Cell Sci 122: 3749-3758

Preuss ML, Schmitz AJ, Thole JM, Bonner HKS, Otegui MS, Nielsen E (2006) A role for the RabA4b effector protein PI-4Kbeta1 in polarized expansion of root hair cells in Arabidopsis thaliana. $\mathbf{J}$ Cell Biol 172: 991-998

Preuss ML, Serna J, Falbel TG, Bednarek SY, Nielsen E (2004) The Arabidopsis Rab GTPase RabA4b localizes to the tips of growing root hair cells. Plant Cell 16: 1589-1603

Qi X, Zheng H (2011) Arabidopsis TRAPPII is functionally linked to Rab-A, but not Rab-D in polar 
protein trafficking in trans-Golgi network. Plant Signal Behav 6: 1679-1683

Qi X, Zheng H (2013) Rab-A1c GTPase defines a population of the trans-Golgi network that is sensitive to endosidin1 during cytokinesis in Arabidopsis. Mol Plant 6: 847-859

Rehman RU, Stigliano E, Lycett GW, Sticher L, Sbano F, Faraco M, Dalessandro G, Di Sansebastiano G-P (2008) Tomato Rab11a characterization evidenced a difference between SYP121dependent and SYP122-dependent exocytosis. Plant Cell Physiol 49: 751-766

\section{Reichardt I, Slane D, El Kasmi F, Knöll C, Fuchs R, Mayer U, Lipka V, Jürgens G (2011)}

Mechanisms of functional specificity among plasma-membrane syntaxins in Arabidopsis. Traffic Cph Den 12: $1269-1280$

Rutherford S, Moore I (2002) The Arabidopsis Rab GTPase family: another enigma variation. Curr Opin Plant Biol 5: 518-528

Saint-Jore CM, Evins J, Batoko H, Brandizzi F, Moore I, Hawes C (2002) Redistribution of membrane proteins between the Golgi apparatus and endoplasmic reticulum in plants is reversible and not dependent on cytoskeletal networks. Plant J Cell Mol Biol 29: 661-678

Saito C, Ueda T (2009) Chapter 4: functions of RAB and SNARE proteins in plant life. Int Rev Cell Mol Biol 274: 183-233

Sanderfoot A (2007) Increases in the number of SNARE genes parallels the rise of multicellularity among the green plants. Plant Physiol 144: 6-17

Sanderfoot AA, Kovaleva V, Bassham DC, Raikhel NV (2001) Interactions between syntaxins identify at least five SNARE complexes within the Golgi/prevacuolar system of the Arabidopsis cell. Mol Biol Cell 12: 3733-3743

Sasvari Z, Kovalev N, Gonzalez PA, Xu K, Nagy PD (2018) Assembly-hub function of ERlocalized SNARE proteins in biogenesis of tombusvirus replication compartment. PLoS Pathog 14: e1007028

Schmitt HD, Wagner P, Pfaff E, Gallwitz D (1986) The ras-related YPT1 gene product in yeast: A GTP-binding protein that might be involved in microtubule organization. Cell 47: 401-412

Shi W, Zeng Q, Kunkel BN, Running MP (2016) Arabidopsis Rab Geranylgeranyltransferases Demonstrate Redundancy and Broad Substrate Specificity in Vitro. J Biol Chem 291: 1398-1410

Singh MK, Jürgens G (2018) Specificity of plant membrane trafficking - ARFs, regulators and coat proteins. Semin Cell Dev Biol 80: 85-93

Siniossoglou S, Peak-Chew SY, Pelham HR (2000) Ric1p and Rgp1p form a complex that catalyses nucleotide exchange on Ypt6p. EMBO J 19: 4885-4894

Slane D, Reichardt I, El Kasmi F, Bayer M, Jürgens G (2017) Evolutionarily diverse SYP1 QaSNAREs jointly sustain pollen tube growth in Arabidopsis. Plant J Cell Mol Biol 92: 375-385

Söllner T, Whiteheart SW, Brunner M, Erdjument-Bromage H, Geromanos S, Tempst P, Rothman JE (1993) SNAP receptors implicated in vesicle targeting and fusion. Nature 362: 318-324 
Srivastava R, Zalisko BE, Keenan RJ, Howell SH (2017) The GET System Inserts the TailAnchored Protein, SYP72, into Endoplasmic Reticulum Membranes. Plant Physiol 173: 1137-1145

Stefano G, Renna L, Chatre L, Hanton SL, Moreau P, Hawes C, Brandizzi F (2006) In tobacco leaf epidermal cells, the integrity of protein export from the endoplasmic reticulum and of ER export sites depends on active COPI machinery. Plant J Cell Mol Biol 46: 95-110

Sutter J-U, Campanoni P, Blatt MR, Paneque M (2006) Setting SNAREs in a different wood. Traffic Cph Den 7: 627-638

Szumlanski AL, Nielsen E (2009) The Rab GTPase RabA4d Regulates Pollen Tube Tip Growth in Arabidopsis thaliana. Plant Cell 21: 526-544

Thole JM, Vermeer JEM, Zhang Y, Gadella TWJ, Nielsen E (2008) Root hair defective4 encodes a phosphatidylinositol-4-phosphate phosphatase required for proper root hair development in Arabidopsis thaliana. Plant Cell 20: 381-395

Thomas LL, Joiner AMN, Fromme JC (2018) The TRAPPIII complex activates the GTPase Ypt1 (Rab1) in the secretory pathway. J Cell Biol 217: 283-298

Touchot N, Chardin P, Tavitian A (1987) Four additional members of the ras gene superfamily isolated by an oligonucleotide strategy: molecular cloning of YPT-related cDNAs from a rat brain library. Proc Natl Acad Sci U S A 84: 8210-8214

Ueda T, Matsuda N, Anai T, Tsukaya H, Uchimiya H, Nakano A (1996) An Arabidopsis gene isolated by a novel method for detecting genetic interaction in yeast encodes the GDP dissociation inhibitor of Ara4 GTPase. Plant Cell 8: 2079-2091

Ueda T, Yoshizumi T, Anai T, Matsui M, Uchimiya H, Nakano A (1998) AtGDI2, a novel Arabidopsis gene encoding a Rab GDP dissociation inhibitor. Gene 206: 137-143

Uejima T, Ihara K, Goh T, Ito E, Sunada M, Ueda T, Nakano A, Wakatsuki S (2010) GDP-bound and nucleotide-free intermediates of the guanine nucleotide exchange in the Rab5. Vps9 system. J Biol Chem 285: 36689-36697

Uemura T, Kim H, Saito C, Ebine K, Ueda T, Schulze-Lefert P, Nakano A (2012) Qa-SNAREs localized to the trans-Golgi network regulate multiple transport pathways and extracellular disease resistance in plants. Proc Natl Acad Sci U S A 109: 1784-1789

Uemura T, Nakano RT, Takagi J, Wang Y, Kramer K, Finkemeier I, Nakagami H, Tsuda K, Ueda T, Schulze-Lefert P, et al (2019) A Golgi-Released Subpopulation of the Trans-Golgi Network Mediates Protein Secretion in Arabidopsis. Plant Physiol 179: 519-532

Uemura T, Suda Y, Ueda T, Nakano A (2014) Dynamic behavior of the trans-golgi network in root tissues of Arabidopsis revealed by super-resolution live imaging. Plant Cell Physiol 55: 694-703

Ul-Rehman R, Rinalducci S, Zolla L, Dalessandro G, Di Sansebastiano GP (2011) Nicotiana tabacum protoplasts secretome can evidence relations among regulatory elements of exocytosis mechanisms. Plant Signal Behav 6: 1140-1145

Varlamov O, Volchuk A, Rahimian V, Doege CA, Paumet F, Eng WS, Arango N, Parlati F, 
Ravazzola M, Orci L, et al (2004) i-SNAREs: inhibitory SNAREs that fine-tune the specificity of membrane fusion. J Cell Biol 164: 79-88

Vernoud V, Horton AC, Yang Z, Nielsen E (2003) Analysis of the small GTPase gene superfamily of Arabidopsis. Plant Physiol 131: 1191-1208

Vukašinović N, Žárský V (2016) Tethering Complexes in the Arabidopsis Endomembrane System. Front Cell Dev Biol. doi: 10.3389/fcell.2016.00046

Waghmare S, Lefoulon C, Zhang B, Liliekyte E, Donald N, Blatt MR (2019) K+ Channel-SEC11 Binding Exchange Regulates SNARE Assembly for Secretory Traffic. Plant Physiol 181: 1096-1113

Waghmare S, Lileikyte E, Karnik R, Goodman JK, Blatt MR, Jones AME (2018) SNAREs SYP121 and SYP122 Mediate the Secretion of Distinct Cargo Subsets. Plant Physiol 178: 1679-1688

Wattelet-Boyer V, Brocard L, Jonsson K, Esnay N, Joubès J, Domergue F, Mongrand S, Raikhel N, Bhalerao RP, Moreau P, et al (2016) Enrichment of hydroxylated C24- and C26-acyl-chain sphingolipids mediates PIN2 apical sorting at trans-Golgi network subdomains. Nat Commun 7: 12788

Wojtas M, Swiezewski S, Sarnowski TJ, Plochocka D, Chelstowska A, Tolmachova T, Swiezewska E (2007) Cloning and characterization of Rab Escort Protein (REP) from Arabidopsis thaliana. Cell Biol Int 31: 246-251

Woollard AAD, Moore I (2008) The functions of Rab GTPases in plant membrane traffic. Curr Opin Plant Biol 11: 610-619

Worden N, Wilkop TE, Esteve VE, Jeannotte R, Lathe R, Vernhettes S, Weimer B, Hicks G, Alonso J, Labavitch J, et al (2015) CESA TRAFFICKING INHIBITOR inhibits cellulose deposition and interferes with the trafficking of cellulose synthase complexes and their associated proteins KORRIGAN1 and POM2/CELLULOSE SYNTHASE INTERACTIVE PROTEIN1. Plant Physiol 167: 381-393

Xia L, Mar Marquès-Bueno M, Bruce CG, Karnik R (2019) Unusual Roles of Secretory SNARE SYP132 in Plasma Membrane H+-ATPase Traffic and Vegetative Plant Growth. Plant Physiol 180: $837-858$

Xing J, Li X, Wang X, Lv X, Wang L, Zhang L, Zhu Y, Shen Q, Baluška F, Šamaj J, et al (2019) Secretion of Phospholipase D $\delta$ Functions as a Regulatory Mechanism in Plant Innate Immunity. Plant Cell 31: 3015-3032

Xing S, Mehlhorn DG, Wallmeroth N, Asseck LY, Kar R, Voss A, Denninger P, Schmidt VAF, Schwarzländer M, Stierhof Y-D, et al (2017) Loss of GET pathway orthologs in Arabidopsis thaliana causes root hair growth defects and affects SNARE abundance. Proc Natl Acad Sci U S A 114: E1544-E1553

Xue Y, Yang Y, Yang Z, Wang X, Guo Y (2018) VAMP711 Is Required for Abscisic AcidMediated Inhibition of Plasma Membrane H+-ATPase Activity. Plant Physiol 178: 1332-1343

Yang X, Liao C-Y, Tang J, Bassham DC (2019) Overexpression of trans-Golgi network t-SNAREs 
rescues vacuolar trafficking and TGN morphology defects in a putative tethering factor mutant. Plant $\mathrm{J}$ Cell Mol Biol 99: 703-716

Yun HS, Kwaaitaal M, Kato N, Yi C, Park S, Sato MH, Schulze-Lefert P, Kwon C (2013) Requirement of vesicle-associated membrane protein 721 and 722 for sustained growth during immune responses in Arabidopsis. Mol Cells 35: 481-488

Zhang B, Karnik R, Alvim J, Donald N, Blatt MR (2019) Dual Sites for SEC11 on the SNARE SYP121 Implicate a Binding Exchange during Secretory Traffic. Plant Physiol 180: 228-239

Zhang B, Karnik R, Waghmare S, Donald N, Blatt MR (2017) VAMP721 Conformations Unmask an Extended Motif for K+ Channel Binding and Gating Control. Plant Physiol 173: 536-551

Zhang B, Karnik R, Wang Y, Wallmeroth N, Blatt MR, Grefen C (2015) The Arabidopsis RSNARE VAMP721 Interacts with KAT1 and KC1 K+ Channels to Moderate K+ Current at the Plasma Membrane. Plant Cell 27: 1697-1717

Zhang X, Zhao H, Gao S, Wang W-C, Katiyar-Agarwal S, Huang H-D, Raikhel N, Jin H (2011) Arabidopsis Argonaute 2 regulates innate immunity via miRNA393(*)-mediated silencing of a Golgilocalized SNARE gene, MEMB12. Mol Cell 42: 356-366

Zheng H, Camacho L, Wee E, Batoko H, Legen J, Leaver CJ, Malhó R, Hussey PJ, Moore I (2005) A Rab-E GTPase mutant acts downstream of the Rab-D subclass in biosynthetic membrane traffic to the plasma membrane in tobacco leaf epidermis. Plant Cell 17: 2020-2036

Zhu XF, Liu Y, Gai XT, Zhou Y, Xia ZY, Chen LJ, Duan YX, Xuan YH (2019) SNARE proteins SYP22 and VAMP727 negatively regulate plant defense. Plant Signal Behav 14: 1610300

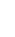

